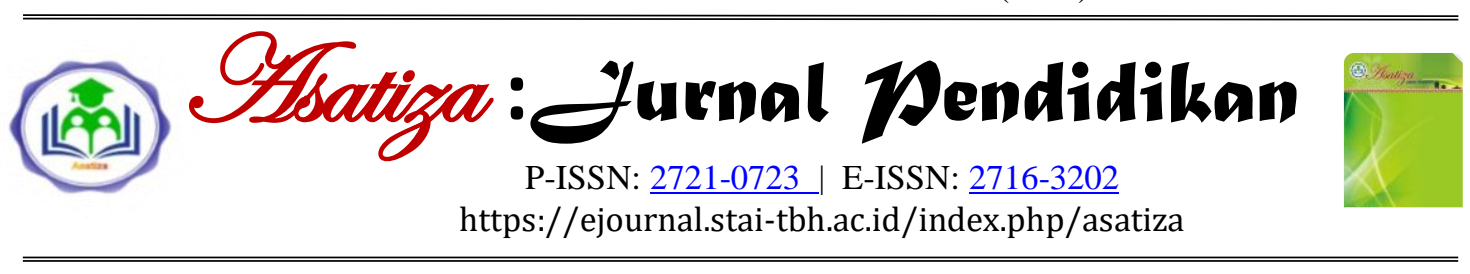

\title{
Living Quran: Pembiasaan Membaca Asmaul Husna di Sekolah Dasar
}

\author{
Fahrul Usmi ${ }^{1, a}$, "Raja Muhammad Kadri ${ }^{2, b}$ \\ ${ }^{1}$ Widyaiswara Ahli Madya BDK, Padang, Sumatera Barat, Indonesia \\ ${ }^{2}$ Alumnus Pascasarjana UIN Imam Bonjol, Padang, Sumatera Barat, Indonesia \\ a fahrulusmi33@gmail.com, ${ }^{b}$ rajamuhammadkadri96@gmail.com
}

\begin{tabular}{|c|c|}
\hline $\begin{array}{l}\text { INFORM } \\
\text { ARTIKEI }\end{array}$ & \\
\hline Histori Ar & tikel: \\
\hline Diterima & :05/07/2021 \\
\hline Direvisi & : 27/09/2021 \\
\hline Disetujui & : 28/09/2021 \\
\hline Diterbitkan & : 30/09/2021 \\
\hline
\end{tabular}

Keywords:

Living Quran, Asmaul Husna, SD Sabbihisma 2 Padang

\section{Kata Kunci: \\ Living Quran, Asmaul \\ Husna, SD Sabbihisma 2 Padang}

\section{DOI:}

https://doi.org/10.46963/ asatiza.v2i3.362

\section{*Correspondence}

Author:

rajamuhammadkadri96@ gmail.com

\begin{abstract}
This paper is a research report on the practice of living Quran in school toward habituating the reading of Asmaul Husna. The purpose of this study was to explore its implementation in the primary school (SD) Sabbihisma 2 Padang. The design was descriptive qualitative research by collecting the data using observation, interviews, and documentation. The findings show that, first, the habit of reading Asmaul Husna has been a long program and characteristic of SD Sabbihisma. Second, in reading Asmaul Husna there was a particular rhythm called the Hijaz rhythm. Third, the reading was accomplished by students every day before the class and during the recitation program at weekly and monthly meetings. Fourth, reading Asmaul Husna was guided by the classroom teacher or teacher who entered in the first hour, it was also led by a teacher/Ustaz. Fifth, the purpose or motivation in reading Asmaul Husna was to expect rewards and heaven from Allah.
\end{abstract}

\begin{abstract}
Abstrak
Tulisan ini merupakan laporan penelitian lapangan mengenai praktik living Quran di sekolah yaitu berupa pembiasaan membaca Asmaul Husna. Tujuan penelitian ini adalah untuk mengetahui bagaimana pelaksanaan living Quran di sekolah SD Sabbihisma 2 Padang. Metode yang digunakan dalam penelitian ini adalah penelitian kualitatif deskriptif yang dalam pengumpulan datanya menggunakan observasi, wawancara dan dokumentasi. Hasil penelitian menunjukkan bahwa pertama, pembiasaan membaca Asmaul Husna sudah sejak lama menjadi program dan ciri khas SD Sabbihisma. Kedua, dalam membaca Asmaul Husna ada irama tertentu yang disebut dengan irama Hijaz. Ketiga, pembacaan Asmaul Husna dilakukan oleh siswa setiap harinya sebelum memulai pembelajaran, dibaca pada setiap acara pengajian dan pertemuan mingguan dan bulanan. Keempat, pembacaan Asmaul Husna sebelum memulai pembelajaran dibimbing oleh wali kelas atau guru yang masuk pada jam pertama dan pada acara pengajian dipimpin oleh seorang guru/ustaz. Kelima, tujuan atau motivasi dalam membaca Asmaul Husna adalah mengharap pahala dan surga dari Allah.
\end{abstract}

\section{Cara mensitasi artikel:}

Usmi, F., \& Kadri, R. M. (2021). Living Al-Quran: Pembiasaan membaca asmaul husna di Sekolah Dasar. Asatiza: Jurnal Pendidikan, 2(3), 188-196. https://doi.org/10.46963/asatiza.v2i3.362

\section{PENDAHULUAN}

Al-Quran secara bahasa apabila ditelusuri akar katanya, merupakan mashdar (infinitif) dari kata qara'ayaqra'u- qira'atan-qur'anan yang artinya bacaan (Ilyas, 2014). Beberapa ayat dalam Al-Quran berisi perintah untuk membaca Al-Quran, salah satunya terdapat pada wahyu yang pertama kali diturunkan yaitu surat Al-Alaq 1-5. Namun, ada dua kata

Editorial Address: Kampus STAI Auliaurrasyidin Tembilahan 
yang berbeda yang digunakan Al-Quran untuk menunjuk makna "membaca" yaitu apabila pembacaan itu berorientasi pada pemahaman, maka kata yang digunakan biasa adalah qiraah, sedangkan apabila pembacaan yang berorientasi pada pengamalan digunakan kata tilawah. Jadi, dapat dipahami bahwa tujuan Al-Quran itu diturunkan adalah untuk dibaca dan dipahami, kemudian setelah dipahami isinya, dituntut untuk mengamalkan isi ajaran yang terdapat di dalamnya.

Seiring dengan antusiasnya para peneliti dan pengkaji Al-Quran, maka muncul berbagai model kajian terhadap Al-Quran baik itu dari segi metode yang digunakan dalam memahami dan menafsirkan Al-Quran hingga kepada orientasi kajian Al-Quran.

Junaedi (2015) mengungkapkan bahwa kajian Al-Quran pada dewasa ini tidak lagi hanya berkutat pada teks-teks ayat Al-Quran, tetapi sudah mulai mengkaji pengamalan masyarakat terhadap ayat-ayat Al-Quran itu sendiri. Praktik-praktik pengamalan terhadap ajaran Al-Quran di dalam kehidupan masyarakat sehari-hari ini dikenal dengan istilah living Quran.

Menurut (Chirzin, 2007), praktikpraktik pengamalan terhadap ajaran AlQuran ini terjadi karena ke seringan individu berinteraksi dengan Al-Quran sehingga menghasilkan pemahaman dan penghayatan terhadap ayat-ayat Al-Quran itu sendiri.

Pemahaman dan penghayatan terhadap Al-Quran tersebut kemudian diungkapkan dan dikomunikasikan secara verbal maupun dalam bentuk tindakan yang dipraktikkan, kemudian mempengaruhi orang lain sehingga melahirkan tindakan-tindakan kolektif dan terorganisasi.

Beberapa penelitian menunjukkan bahwa di sekolah juga ditemukan praktikpraktik pengamalan terhadap ajaran AlQuran (living Quran) misalnya penelitian Kholis (2017) yang menunjukkan bahwa beberapa praktik pengamalan terhadap ajaran Al-Quran. Penelitian yang dilakukan di SD Islam dan SMP Islam AlAzhar Tulungagung tersebut menghasilkan gambaran bahwa sekolah tersebut menerapkan nilai-nilai yang terkandung dalam Al-Quran seperti kesalehan dan kesopanan, gerakan membaca Al-Quran (tadarus), menghafal Al-Quran, mendalami makna Al-Quran, membaca surat-surat atau bacaan tertentu yang sesuai dengan petunjuk dari AlQuran.

Di Kota Padang sendiri penulis juga menemukan beberapa sekolah yang mencoba menerapkan nilai-nilai dan ajaran-ajaran yang terkandung di dalam Al-Quran salah satunya yaitu SD Sabbihisma 2. Berdasarkan penelitian (Danil, 2018) SD Sabbihisma 2 merupakan salah satu sekolah yang telah sejak lama menyelenggarakan pendidikan yang bernuansa keislaman dan berbasis ajaran Al-Quran. Ada berbagai kegiatan keagamaan yang dilaksanakan di sekolah tersebut seperti membaca Al-Quran, menghafal Al-Quran, shalat berjamaah, didikan subuh, peringatan hari-hari besar Islam dan pembiasaan membaca Asmaul Husna.

Penulis merasa tertarik untuk mengungkap mengenai pembiasaan membaca Asmaul Husna ini, karena 
bacaan ini selalu dirutinkan membacanya pada lembaga pendidikan ini pada setiap kegiatan.

Apabila ditelusuri, pembacaan Asmaul Husna ini memiliki dasar dan merupakan perintah dari ajaran Al-Quran yaitu sebagai berikut:

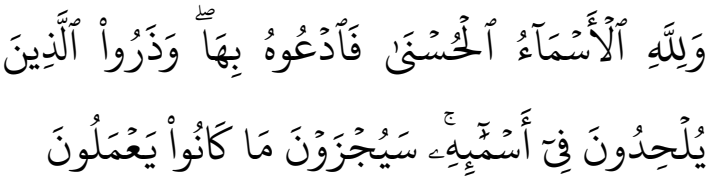

Artinya: Hanya milik Allah Asmaaul husna, maka bermohonlah kepada-Nya dengan menyebut Asmaa-ul Husna itu dan tinggalkanlah orang-orang yang menyimpang dari kebenaran dalam (menyebut) nama-nama-Nya. Nanti mereka akan mendapat balasan terhadap apa yang telah mereka kerjakan. (QS. AlA'raf: 180)

Di ayat yang lain Al-Quran juga memerintahkan untuk menyebut (membaca) asmaul husna, yaitu:

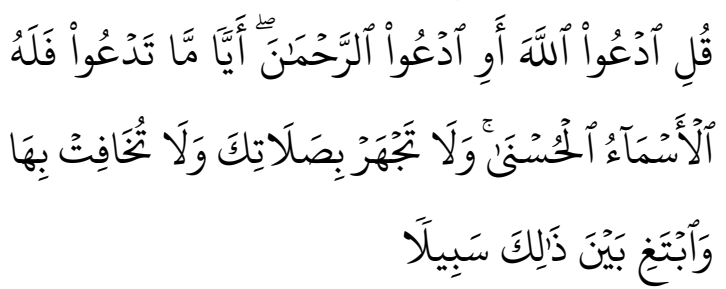$$
\text { وَابْتَتْغ بَيْنَ ذَلِلكَ سَبِيًََ }
$$

Artinya: Katakanlah: "Serulah Allah atau serulah Ar-Rahman. Dengan nama yang mana saja kamu seru, Dia mempunyai Al Asmaaul husna (namanama yang terbaik) dan janganlah kamu mengeraskan suaramu dalam shalatmu dan janganlah pula merendahkannya dan carilah jalan tengah di antara kedua itu". (QS. Al-Isra': 110)

Kedua ayat di atas juga di dukung dan di perjelas oleh hadis Nabi Muhammad SAW. Sebagai berikut.
إنَّ لِلَّهِهِ تِنْعَة وتِتْعِينَ اسْمَا مِاعَةَ الأَ وَاحِدًا مَنْ أَحْصَاهَا دَخَلَ الجْنًَََّ

Artinya: "Sesungguhnya Allah memiliki Sembilan puluh Sembilan namaseratus kurang satu- siapa yang ahshaha' (mengetahui/menghafal/menghitung/mem eliharanya) maka dia masuk ke surga" (HR. Bukhari)

Berdasarkan uraian di atas diketahui bahwa pembiasaan membaca Asmaul hasan merupakan bagian dari mempraktikkan ajaran Al-Quran atau yang disebut dengan istilah living Quran.

\section{METODE}

Penelitian living Quran yang penulis lakukan termasuk ke dalam penelitian kualitatif deskriptif. Adapun dalam mengumpulkan data penulis menggunakan tiga cara yang ditawarkan oleh para Pakar di bidang ini (Yusuf, 2007) yaitu sebagai berikut:

\section{Observasi}

Observasi ini dilakukan dalam rangka memahami, mencari jawab, menemukan bukti terhadap fenomena sosial-keagamaan terkait dengan topik penelitian.

\section{Wawancara}

Wawancara dilakukan untuk memperkuat informasi yang telah dikumpulkan melalui observasi, untuk memperoleh informasi yang belum terungkap dalam observasi dan untuk mengkonfirmasi terhadap apa yang telah diamati atau diobservasi. Agar pertanyaan-pertanyaan yang diajukan oleh peneliti memperoleh jawaban yang valid dan akurat maka diharapkan peneliti menemukan key person (tokoh-tokoh kunci) yang akan dimintai keterangan. 
Dalam penelitian ini penulis menggunakan wawancara tertutup dalam memperoleh data yang diperlukan.

\section{Dokumentasi}

Dokumentasi digunakan untuk mendukung dua metode pengumpulan data di atas agar lebih valid dan meyakinkan.

\section{HASIL DAN PEMBAHASAN \\ Temuan Umum}

SD Sabbihisma 2 merupakan salah satu lembaga pendidikan tingkat dasar yang bernaung di bawah yayasan Perguruan Sabbihisma. Perguruan Sabbihisma sendiri merupakan suatu lembaga yang bergerak di bidang pendidikan dan dakwah Islam yang lahir dalam rangka memenuhi kebutuhan masyarakat Sumatera Barat khususnya kota Padang akan sekolah yang berbasis agama dan bercirikan Al-Quran.

Perguruan Sabbihisma berdiri pada tahun 1996 yang diketuai oleh H. Zulkifli Imam Said. Cikal bakal berdirinya Perguruan Sabbihisma ini adalah bertemunya H. Zulkifli Imam Said dengan beberapa pemuda yang tergabung dalam organisasi Badan Komunikasi Pemuda Remaja Masjid Indonesia (BKPRMI) Sumatera Barat yang mempunyai cita-cita yang sama yaitu ingin mewujudkan satu lembaga pendidikan Islam yang berbasis Al-Quran di kota Padang.

Lembaga pendidikan Perguruan Sabbihisma dalam kegiatan kesehariannya selain melaksanakan pembelajaran dengan kurikulum dinas pendidikan juga ditambah dengan pembelajaran khusus bagi siswanya yaitu Pembelajaran Al-Quran berupa Tahfiz dan Tadarus (Baca Tulis AlQuran), hal itu merupakan perwujudan dari moto Perguruan Sabbihisma yaitu "Sekolah Langsung Mengaji". Saat ini Perguruan Sabbihisma telah mempunyai beberapa unit satuan pendidikan dalam berbagai jenjang, mulai dari TK 7 buah, SD 4 buah, dan SMP \& SMA Plus Pesantren 1 buah.

\section{Temuan Khusus}

Berdasarkan penelitian yang telah penulis lakukan, maka ada beberapa temuan yang perlu penulis paparkan yaitu sebagai berikut.

Pertama, pembacaan Asmaul hasan ini sudah menjadi program SD Sabbihisma sejak awal mula berdirinya, dan merupakan salah satu ciri khas dari yayasan perguruan Sabbihisma. Hal ini seperti diungkapkan oleh kepala sekolah SD Sabbihisma pada saat wawancara pada tanggal 20 Januari 2021 sebagai berikut. "memang Asmaul Husna ini adalah salah satu program yang menjadi ciri khas yayasan perguruan Sabbihisma dan telah kami laksanakan sejak awal yang berdirinya pada tahun 1996. karena, salah satu cara untuk mempromosikan suatu sekolah atau lembaga pendidikan agar dikenal orang, maka dia harus punya ciri khas tersendiri"

Kedua, berdasarkan pengamatan yang penulis lakukan, pembacaan Asmaul Husna ini dilakukan dengan menggunakan irama tersendiri, yang dengan diawali dengan ta'awudz dan basmalah terlebih dahulu. Kemudian membaca "nasaluka ya man huwallahullazi laa ilaa ha illahu...... setelah itu dilanjutkan dengan menyebutkan Asmaul Husna dari awal sampai akhir". Mengenai hal ini kepala sekolah (20 Januari 2021) juga mengungkapkan: "dalam membaca 
Asmaul Husna ini ada banyak versi irama tersendiri, diantaranya ada versi yang dipopulerkan oleh seorang motivator Ary Ginanjar, tetapi kami di sini menggunakan versi irama yang lain, yaitu dengan irama Hijaz"

Ketiga, dari pengamatan yang penulis lakukan pembacaan Asmul Husna ini dilakukan pada beberapa waktu tertentu yaitu pada setiap harinya sebelum memulai pembelajaran formal terlebih dahulu dibacakan Asmaul Husna setelah berdoa. Selanjutnya pada acara pengajian mingguan dan pada acara pengajian bulanan. Pengamatan yang penulis lakukan selama meneliti ini juga dibenarkan oleh kepala sekolah: "pembacaan Asmaul Husna ini dilakukan hampir setiap harinya oleh siswa kami di sini, yaitu setiap sebelum memulai pembelajaran wajib. Selain itu juga pada hari biasanya (sebelum pandemi) juga ada semacam ekstrakurikuler pengembangan bakat dengan membaca Asmaul Husna pada setiap hari Selasa pembacaan Asmaul Husna masing-masing kelas secara bergiliran. Selanjutnya Asmaul Husna ini juga dibacakan pada setiap kali pertemuan atau acara pengajian/wirid mingguan, juga dalam acara pengajian/wirid bulanan (sekaligus terima rapor bulanan).

Keempat, berdasarkan pengamatan penulis pembacaan Asmaul Husna di dalam kelas sebelum belajar dibimbing oleh wali kelas atau bisa juga oleh guru yang mengajar jam pertama. Sedangkan pada acara pengajian mingguan dan bulanan pembacaan Asmaul Husna ini dipimpin oleh salah seorang ustad/guru SD Sabbihisma secara bergiliran setiap kali pertemuannya.
Kelima, motivasi atau tujuan membaca Asmaul Husna ini latarbelakangi oleh keyakinan bahwa orang yang membacanya akan meraih surga. Hal diungkapkan oleh salah seorang ustaz/guru SD Sabbihisma pada saat wawancara pada tanggal 21 Januari 2021 yang menyatakan: "membaca Asmaul Husna ini adalah salah satu zikir atau cara kita mengingat Allah. Dan ada hadis Nabi yang menyatakan bahwa barang siapa yang menzikirkan Asmaul Husna maka akan mendapatkan surganya Allah. Selain itu perintah untuk membaca zikir Asmaul Husna ini juga disebutkan di dalam AlQuran.

\section{Analisis Temuan}

Berdasarkan dalil-dalil yang ditemukan, Asmaul Husna merupakan salah satu konten/isi teks ajaran yang disebutkan di dalam Al-Quran dan diperintahkan untuk membacanya. Jadi apa yang dilakukan oleh SD Sabbihisma dengan membiasakan membaca Asmaul Husna merupakan wujud dari pengamalan dari ayat-ayat Al-Quran atau disebut dengan istilah living Quran. Living Quran yang dimaksud adalah terlihat fakta sosial masyarakat muslim (dalam hal ini sekolah SD Sabbihisma 2) menyikapi, merespons dan mempraktikkan sisi-sisi Al-Quran secara kultural sebagai pemahaman terhadap Al-Quran itu sendiri. Adapun ayat Al-Quran yang diamalkan atau dipraktikkan yaitu:

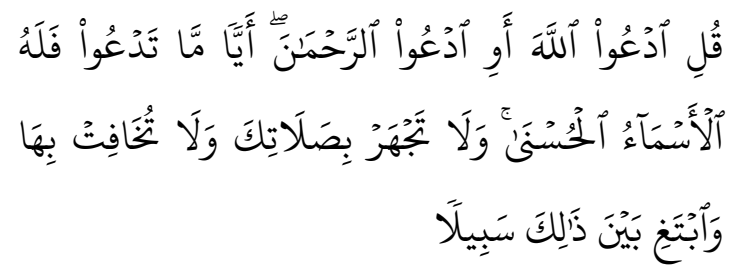


Fahrul Usmi \& Raja Muhammad Kadri

Artinya: Katakanlah: "Serulah Allah atau serulah Ar-Rahman. Dengan nama yang mana saja kamu seru, Dia mempunyai al asmaaul husna (namanama yang terbaik) dan janganlah kamu mengeraskan suaramu dalam shalatmu dan janganlah pula merendahkannya dan carilah jalan tengah di antara kedua itu". (QS. Al-Isra': 110.)

Shihab (2004) mengungkapkan bahwa ayat tersebut memerintahkan untuk menyeru Tuhan Yang Maha Esa dengan nama Allah atau dengan nama ArRahman. Dengan nama yang mana saja diseru diantara semua nama-nama-Nya maka itu adalah baik. Allah mempunyai Asmaul Husna yakni nama-nama terbaik. Oleh sebab itu tidak perlu ragu menyebut salah satu nama itu atau ke semuanya.

Membaca Asmaul Husna secara umum dianjurkan pada setiap kesempatan dan waktu. Tetapi ada ayat Al-Quran yang menganjurkan untuk menyebutkan atau membaca Asmaul Husna ketika sedang bermohon atau berdoa kepada Allah SWT.

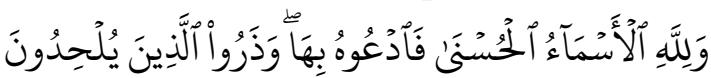

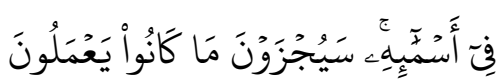

Artinya: Hanya milik Allah Asmaaul Husna, maka bermohonlah kepada-Nya dengan menyebut Asmaa-ul Husna itu dan tinggalkanlah orang-orang yang menyimpang dari kebenaran dalam (menyebut) nama-nama-Nya. Nanti mereka akan mendapat balasan terhadap apa yang telah mereka kerjakan. (QS. AlA'raf: 180)

Ayat di atas mengajak manusia untuk berdoa /menyeru-Nya dengan sifat/ nama-nama yang terbaik itu. Salah satu makna dari perintah ini adalah ajakan untuk menyesuaikan kandungan permohonan dengan sifat yang disandang
Allah. Menyebut sifat-sifat Allah yang sesuai dengan permohonan akan dapat mengundang terkabulnya doa, selain itu juga akan melahirkan ketenangan dan optimisme dalam jiwa si pemohon (Shihab, 2004).

Perintah ayat Al-Quran ini secara kolektif di SD Sabbihisma belum terlihat, karena pembacaan Asmaul Husna selama ini hanya dilakukan tidak dalam keadaan ketika sedang bermohon/berdoa kepada Allah. Walaupun begitu yang pasti perintah Al-Quran membaca Asmaul Husna telah dilaksanakan.

Selanjutnya mengenai irama, AlQuran maupun hadis Nabi Muhammad SAW tidak menyebutkan secara khusus teknis dalam membaca Asmaul Husna, perintahnya secara umum hanyalah membacanya. Oleh sebab itu irama yang digunakan oleh SD Sabbihisma dalam membawakan Asmaul Husna ini bisa tidak bertentangan dengan al-Qur'an maupun hadis Nabi Muhammad SAW, sehingga hal ini dibolehkan.

Motivasi atau tujuan dalam membaca Asmaul hasan di SD Sabbihisma adalah untuk mengharapkan pahala dan surga, hal ini sesuai dengan hadis Nabi Muhammad SAW sebagai berikut.

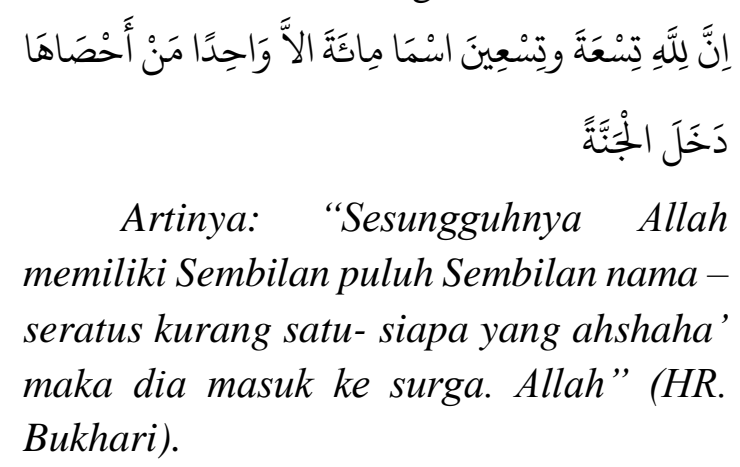

Artinya: "Sesungguhnya Allah memiliki Sembilan puluh Sembilan namaseratus kurang satu- siapa yang ahshaha' maka dia masuk ke surga. Allah" (HR. Bukhari). 
Menurut Imam Nawawi, penafsiran ulama mengenai kata "Ahshaha" diantara maksudnya adalah dalam rangka membacanya, mempercayainya dan melaksanakan kandungannya atau meneladaninya. Berdasarkan hal itu pula Quraish Shihab dalam kitab Tafsir AlMisbah ketika membahas ayat tentang Asmaul Husna menyatakan bahwa baik yang membaca, menghafal, memahami dan mengamalkan kandungannya, semua akan memperoleh curahan rahmat ilahi atas niat dan usahanya.

Jadi selain menghafal dan membacanya, sifat-sifat Allah yang ada dalam Asmaul Husna ini juga diharapkan bisa untuk diteladani dan dicontoh oleh makhluknya. Dalam hal ini Quraish Shihab dalam bukunya Yang Hilang Dari kita: Akhlak, mengutip dan memaparkan sebuah ungkapan yaitu

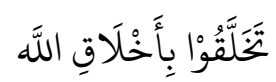

Artinya: Berakhlaklah kalian dengan akhlak/sifat-sifat Allah

Ungkapan tersebut ada yang menyebutnya sebagai hadis dan diperselisihkan oleh para ulama mengenai keshahihannya, tetapi sangat populer di kalangan pakar-pakar tasawuf. Bahkan menurut Imam Al-Ghazali seluruh sifatsifat Allah dapat diteladani oleh manusia, kecuali sifat Ketuhanan-Nya. Karena sifat manusia yang terpuji adalah sifat dan tingkah lakunya yang meneladani sifatsifat Allah. (Shihab, 2019).

Pembiasaan membaca Asmaul Husna ini merupakan langkah awal untuk mengamalkan dan meneladani sifat-sifat Allah yang ada didalamnya.
Pembiasaan membaca Asmaul Husna ini memang sangat tepat dibiasakan untuk anak-anak usia Sekolah Dasar. Karena menurut Zakiah (1970) Anak-anak sampai menjelang umur 12 tahun belum mampu berpikir abstrak, oleh karena itu agama harus diberikan dalam jangkauannya, oleh sebab itu, penting pembiasaan-pembiasaan bagi anak-anak dalam mengajarkan sesuatu terutama pendidikan agama.

Menurut Ilmu Psikologi Agama, (Sururin, 2004) pada usia 6-12 tahun, anak-anak belajar mengenal Tuhan melalui ucapan orang-orang yang ada di sekelilingnya dan melihat perilaku orangorang yang mengungkapkan rasa kagumnya kepada Tuhan. Oleh sebab itu dibutuhkan peran orang tua dan guru dalam memperkenalkan dan membiasakan anak untuk melakukan tindakan-tindakan agama walaupun sifatnya hanya meniru. Pembiasaan-pembiasaan tersebutlah yang akan berpengaruh bagi perkembangan agama anak pada fase selanjutnya.

Zakiah (1994) juga mengungkapkan bahwa pendidikan agama bagi anak didik pada jenjang Sekolah Dasar sebaiknya memang mendahulukan pengenalan sifatsifat Allah yang membawa kepada rasa aman, misalnya Maha Pengasih, Maha Penyayang, Maha Pemurah, Maha Penolong, Maha Pelindung, Maha Mengetahui, Maha Mendengar, Maha Melihat dan sebagainya agar tumbuh sikap cinta dan dekat kepada Allah serta rasa kagum dan menyenangkan. Sedangkan penjelasan terhadap siksaan, azab kubur, neraka dan hukuman-hukuman yang mengerikan, sebisa mungkin untuk ditangguhkan penyampaiannya sampai 
perkembangan kecerdasan anak mampu memahami hal abstrak. Tujuannya supaya tidak muncul sikap-sikap negatif dalam beragama seperti takut, marah dan benci kepada Allah. Atas dasar ini jugalah, pembiasaan membaca Asmaul Husna ini juga sangat tepat untuk dibiasakan oleh anak Sekolah Dasar.

\section{SIMPULAN}

Berdasarkan uraian di atas dapat disimpulkan bahwa:

Pertama, pembiasaan membaca Asmaul Husna sudah sejak lama menjadi program dan ciri khas SD Sabbihisma. Kedua, dalam membaca Asmaul Husna ada irama tertentu yang disebut dengan irama Hijaz. Ketiga, pembacaan Asmaul Husna dilakukan oleh siswa setiap harinya sebelum memulai pembelajaran, dibaca pada setiap acara pengajian dan pertemuan mingguan dan bulanan. Keempat, pembacaan Asmaul Husna sebelum memulai pembelajaran dibimbing oleh wali kelas atau guru yang masuk pada jam pertama dan pada acara pengajian dipimpin oleh seorang guru/ustaz. Kelima, tujuan atau motivasi dalam membaca Asmaul Husna adalah mengharap pahala dan surga dari Allah.

Berdasarkan hasil penelitian ini, maka dapat diajukan rekomendasi penelitian ini sebagai berikut:

Bagi para orang tua dan pendidik, diharapkan untuk membiasakan sesuatu yang baik terhadap anak terutama pada anak usia Sekolah Dasar karena belum mampu untuk berpikir abstrak. Salah satu pembiasaan yang baik adalah membaca Asmaul Husna.

Sedangkan bagi peneliti selanjutnya diharapkan untuk dapat mengembangkan penelitian ini misalnya dengan meneliti pengaruh positif dari pembacaan Asmaul Husna terhadap siswa, atau merancang dan mengembangkan Asmaul Husna sebagai salah satu spirit dalam membentuk karakter siswa.

\section{REFERENSI}

Chirzin, M. (2007). Mengungkap Pangalaman Muslim Berinteraksi dengan Al-Qur'an dalam Metode Penelitian Living Qur'an dan Hadis. Yogyakarta: Teras

Danil, M. (2018). Implementasi full day school di Sekolah Dasar Sabbihisma padang. Jurnal Komunikasi Pendidikan, 2, (1), 88-90. https://doi.org/10.32585/jkp.v2i1.68

Ilyas, Y. (2014). Ulumul Qur'an. Yogyakarta: Itqan Publishing.

Junaedi, D. (2015). Living Qur'an: Sebuah pendekatan baru dalam kajian AlQur'an (Studi kasus di Pondok Pesantren As-Siroj Al-Hasan Desa Kalimukti Kec. Pabedilan Kab. Cirebon. Journal of Qur'an and Hadith Studies, 4(2), 169-190. https://doi.org/10.15408/quhas.v4i2. 2392

Kholis, N. (2017). Implementasi Pendidikan karakter berbasis nilainilai islam melalui budaya sekolah. Edukasi: Jurnal Pendidikan Islam 5(2), 047-065. Retrieved from https://staimtulungagung.ac.id/ejournal/index.ph p/edukasi/article/view/291

Shihab, Q. (2004). Tafsir Al-Misbah Volume 7. Jakarta: Lentera Hati.

Shihab, Q. (2019). Yang Hilang Dari Kita: Akhlak. Jakarta: Lentera Hati.

Sururin. (2004). Ilmu Jiwa Agama. Jakarta: RajaGrafindo Persada, Cet.1. 
Yusuf, M. (2007). Pendekatan Sosiologi Dalam Penelitian Living Qur'an, dalam Metode Penelitian Living Qur'an dan Hadis. Yogyakarta: Teras.

Zakiah, D. (1970). Ilmu Jiwa Agama, Jakarta: Bulan Bintang. Jakarta: Bulan Bintang.

Zakiah, D. (1994). Pendidikan Islam dalam Keluarga dan Sekolah. Jakarta: Ruhama. 